\title{
( \\ Death and organ donation: back to the future
} EDITOR'S CHOICE

\author{
F G Miller
}

Correspondence to:

Dr F G Miller, Department of Bioethics, National Institutes of Health, Building 10, Room 1C118, Bethesda, MD 20892 1156, USA; fmiller@nih.gov

Received 13 April 2009 Revised 21 May 2009 Accepted 5 June 2009

\section{ABSTRACT}

The practice of transplantation of vital organs from "braindead" donors is in a state of theoretical disarray. Although the law and prevailing medical ethics treat patients diagnosed as having irreversible total brain failure as dead, scholars have increasingly challenged the established rationale for regarding these patients as dead. To understand the ethical situation that we now face, it is helpful to revisit the writings of the philosopher Hans Jonas, who forcefully challenged the emerging effort to redefine death in the late 1960s.

The President's Council on Bioethics recently issued a report entitled, "Controversies in the determination of death". "The title signifies the unsettled state of current thinking regarding the determination of death, with fundamental implications for the ethics of vital organ transplantation. A 1981 publication by a predecessor public bioethics body-The President's Commission for the Study of Ethical Problems in Medicine and Biomedical and Behavioral Research-consolidated a consensus regarding the determination of death on neurological criteria and articulated what was then seen as a persuasive rationale for regarding patients diagnosed as having "brain death" as biologically dead. ${ }^{2}$ The acceptance of brain death as death of the human being legitimated the practice of procuring viable vital organs from patients with devastating neurological injury who were still breathing (and perfusing their organs) with the aid of mechanical ventilators. By the late 1990s, however, the equation of brain death with death of the human being was increasingly challenged by scholars, based on evidence regarding the array of biological functioning displayed by patients correctly diagnosed as having this condition who were maintained on mechanical ventilation for substantial periods of time..$^{3-5}$ These patients maintained the ability to sustain circulation and respiration, control temperature, excrete wastes, heal wounds, fight infections and, most dramatically, to gestate fetuses (in the case of pregnant "brain-dead" women). ${ }^{67}$

The thesis propounded by the President's Commission that the "death" of the brain constituted death of the human being, because the integrated functioning of the organism as a whole had ceased, no longer seemed credible to critics of the "whole brain" standard of death. This scholarly criticism was instrumental in prompting the President's Council on Bioethics to re-examine the determination of death, to reject the rationale of the President's Commission for neurological criteria defining death, and to attempt a new (but unpersuasive) account of why patients with "total brain failure" are biologically dead.
Nevertheless, the practice of transplantation with vital organs procured from brain-dead donors has proceeded on the basis of "business as usual", with death declared before extracting organs, consistent with the "dead donor rule". Moreover, the scholarly controversy over determining death has yet to disturb the prevailing understanding within the medical establishment of vital organ donation as based solidly on the thesis that brain death equals death. A recent commentary in the JAMA Classics series, reviewing the landmark 1968 article promulgating the criteria for defining brain death, declared that "The criteria for brain death enumerated in this article have surely held up during the past 40 years". ${ }^{8}$ The author goes on to observe that "identification of an irreversible state of coma has made possible the ethical and practical donation of living organs from patients with brain death". Remarkably, there is no mention of any controversy over whether the clinical state denominated as "brain death" constitutes death of the human being.

In this article I endeavour to illuminate the ethical situation that we now face with respect to the determination of death and vital organ donation by revisiting the perspective of the philosopher Hans Jonas - a pioneer in bioethics. In two papers written between 1968 and 1970, Jonas rejected the emerging concept of brain death and the prospect of procuring vital organs for transplantation from those designated as brain dead. By going back to the thinking of Jonas, during an era when neurological criteria for determining death had yet to be established and organ transplantation was a novel procedure, we can obtain fresh insight into where we are and where we might be going in understanding the connection between death and vital organ donation.

\section{SETTING THE STAGE}

Before examining the details of the position staked out by Jonas, it helps to set the stage. In the 1960s intensive care units had been established and organ transplantation was under development. Medicine faced a problem and an opportunity in the intersection between these two areas of clinical practice. ${ }^{9}$ The problem was how to respond appropriately to the situation of patients with devastating and permanent neurological injury who were hooked up to mechanical ventilators in intensive care units. The opportunity was to take advantage of the fact that these patients, who had no prospect of return to a meaningful human life, were ideal sources of organs for transplantation. In 1968, an Ad Hoc Committee of the Harvard Medical School, headed by the distinguished anaesthesiologist Henry Beecher, produced an article, published in JAMA, defining brain death. ${ }^{10}$ 
This article noted two purposes for establishing "a new criterion for death": "(1) improvements in resuscitative and supportive measures have led to increased efforts to save those who are desperately injured. Sometimes these efforts have led to partial success so that the result is an individual whose heart continues to beat but whose brain is irreversibly damaged. The burden is great on patients who suffer permanent loss of intellect, on their families, on the hospitals, and on those in need of hospital beds already occupied by these comatose patients. (2) Obsolete criteria for definition of death can lead to controversy in obtaining organs for transplantation."

Historical commentators have diverged in evaluating the real motivations of Beecher and the Harvard committee. Some have argued, following the committee's stated position, that organ transplantation was only a secondary concern. The primary motivation was to overcome reluctance on the part of physicians to stop intensive care treatment for brain-dead patients, as continued treatment was of no value for them, a needless burden on their families and a waste of scarce resources. ${ }^{11}$ Others have contended that the first-mentioned and emphasised concern about life-sustaining treatment was a smokescreen masking the primary motivation to legitimate and facilitate organ transplantation-a smokescreen because physicians were already comfortable with stopping treatment for brain-dead patients. ${ }^{12}$

From the dual perspective of examining the views of Jonas and illuminating our current situation, there is no need to take sides on this dispute about the true motivation of the Harvard committee. Jonas was especially concerned with the prospect of using brain-injured patients as a source of organs for transplantation. However matters stood in 1968, by the early 1980s the legality and ethics of withdrawing life-sustaining treatment was not in question. Based on the evolution of law and medical ethics, clinicians became comfortable with withdrawing lifesustaining treatment in a wide range of circumstances that were not predicated on determining that the patient is already dead. ${ }^{13}$ (Ethicists, however, continue to disagree about how to characterise the act of treatment withdrawal-is it merely allowing to die or does it cause death? - and, accordingly, how it differs from or resembles active euthanasia). Instead, we currently face the challenge of providing a coherent and cogent justification of vital organ transplantation in view of the controversy over the status of donors diagnosed as being brain dead.

\section{JONAS ON DEATH AND ORGAN DONATION}

Jonas was one of the first philosophers to engage with the issue of the ethics of human experimentation. In a now classic article on this topic, published in 1969, he devoted the penultimate section to "On the redefinition of death". ${ }^{14} \mathrm{He}$ seized the opportunity to express his strong opposition to the implications for organ donation of the position of the Harvard Ad Hoc Committee. Looking back from the present-from a time when transplantation of vital organs procured from brain-dead patients has become routinised as a standard life-saving procedure-this section looks tacked on and out of place. Indeed, in a later essay elaborating his views on the definition of death and organ transplantation, Jonas ${ }^{15}$ noted that his discussion of this topic in the previous essay was "marginal to the discussion of "experimentation on human subjects." "Yet in 1968, organ transplantation was essentially experimental and unsuccessful as a longer-term treatment, as a result of an inability to solve the problem of organ rejection by the recipient. Moreover, the famous conclusion of Jonas's essay on human experimentation ${ }^{14}$ was apparently also meant to apply to the effort to redefine death in order to facilitate organ transplantation: "Let us not forget that progress is an optional goal, not an unconditional commitment... Let us also remember that a slower progress in the conquest of disease would not threaten society, grievous as it is to those who have to deplore that their particular disease be not yet conquered, but that society would indeed be threatened by the erosion of those moral values whose loss, possibly caused by too ruthless a pursuit of scientific progress, would make its dazzling triumphs not worth having."

In a nutshell, Jonas argued that "brain-dead" patients remained alive, and that using them as a source of vital organs for transplantation was just the sort of erosion of moral values that would threaten the normative foundations of social life.

Jonas contended that there were no grounds for regarding the patient diagnosed as being "brain dead" as a dead human being. We need absolute certainty of death to treat the human body as a corpse or cadaver, from which it may be appropriate to extract organs with the aim of saving the life of another. This, however, is not afforded by the condition of "irreversible coma" that the Harvard committee described as satisfying a new criterion for death. In addition, the nascent rationale that the organism as a whole failed to function in these patients did not hold water according to Jonas. He correctly saw respiration and circulation as central organismic functions, albeit driven by artificial means. Indeed, he opined that the brain-dead organism was capable of "pretty much everything not involving neural control", a thesis that has been borne out by more recent evidence..$^{15}$ In this vein, Shewmon ${ }^{16}$ has demonstrated that, setting aside the capacity for consciousness, the brain-dead patient essentially displays the same pattern of biological functioning and dysfunction as ventilator-dependent quadriplegic patients with high level cervical damage, who unquestionably are alive.

Jonas took pains to emphasise that he had no objection to stopping life-sustaining treatment in these patients-"to cease the artificial prolongation of certain functions (like heartbeat) traditionally regarded as signs of life", and thus to allow them to die. ${ }^{14}$ Allowing to die by stopping treatment is one thing and the lethal act of extracting vital organs in still-living patients is another. Thinking "against the stream"- the title of his followup essay explaining his position on the new definition of death-Jonas got it right concerning the living status of "braindead" patients. They neither appear to be, nor are, corpses or cadavers-a conclusion that has become all the more apparent with greater knowledge about the biological functioning that they maintain with the aid of mechanical ventilation and other measures of routine support. Does it follow that it is wrong to extract vital organs from these patients, as Jonas eloquently contended?

Jonas adduced three arguments against procuring organs from patients in the irreversible coma described as "brain death". First, we cannot be confident that these still heart-beating and breathing human beings are immune from suffering. Indeed, he notes that the prospect of organ extraction from these patients would amount to what would have previously been called "vivisection" and "would be torture and death to any living body" ${ }^{14}$ He acknowledges, however, that this point "is merely a subsidiary and not the real point of my argument". ${ }^{14}$ Second, it is wrongful exploitation to extract vital organs from living patients, no matter how neurologically compromised they may be. Jonas states, "When only permanent coma can be gained with the artificial sustaining of functions, by all means turn off the respirator... and let the patient die; but let him die all the way. Do not, instead, arrest the process and start using him as a 
mine (italics added)." ${ }^{\prime 14}$ Extracting organs before death treats the living being as a thing. In his later essay, Jonas invokes the Kantian injunction against using people merely as a means. The patient in an irreversible coma retains the "sacrosanctity" of a living human being: "That sacrosanctity decrees that it must not be used as a mere means. ${ }^{15}$ Third, for physicians to engage in a practice of lethal organ donation is contrary to the moral vocation of medicine. Consistent with his penchant for strong rhetoric, exhibited in the quotes above, Jonas remarks, "The patient must be absolutely sure that his doctor does not become his executioner, and that no definition authorises him ever to become one". ${ }^{14}$

\section{CRITIOUE}

What are the merits of these arguments? I set aside the first relating to suffering. The neurological condition of patients satisfying the clinical criteria for brain death makes it highly doubtful that they retain the capacity for feeling pain; moreover, any doubts on that score could be addressed by using anaesthesia during the process of organ extraction. With respect to exploitation, Jonas presumably would have had no objection to procuring organs from individuals who were genuinely dead, provided that proper consent to do so was obtained. As Paul Ramsey observed, "Let it be said at once that after it has been determined that a patient has died and doctors and the family are in the presence of an unburied corpse, the corpse itself can certainly be used as a "vital organ bank." dead" patients remain alive, as Jonas contended, are they necessarily being exploited when their organs are procured for transplantation to save the lives of others? In a non-moral sense of the word, they certainly are being exploited, as their vital organs are being used for the purpose of transplantation. The key issue is whether they are merely being used-whether the use is wrongful. In many areas of interpersonal conduct, consent marks the difference between wrongfully using a person merely as a means and morally permissible interaction, as in the differences between slavery and employment, theft and borrowing, rape and permissible sexual intercourse, and treating patients as human guinea pigs and ethical clinical research.

Consider the situation of healthy individuals who donate blood, bone marrow, or a kidney. When they validly consent for such donation, we do not regard them as being wrongfully exploited. They are being used, with their consent, to help save the lives of others; but they are not being treated as a "mine", from which precious resources can be extracted for profit. Why, then, should vital organ procurement from still-living but braindead patients be understood as wrongful exploitation? Although individuals who have the irreversible coma known as brain death are not able to give contemporaneous informed consent, many may have expressed previously their preferences for organ donation. When no previous preferences have been registered or expressed, family members are entitled to consent for organ donation on behalf of the brain-dead individual. To be sure, currently the choice of becoming a "cadaveric" organ donor in the event of brain death is predicated on the premise that to be diagnosed as having this condition is to be dead. The issue here is exploitation, not the justification of causing death in the act of procuring vital organs. Setting aside concerns about whether consent to be killed, in some circumstances, should be regarded as validly authorising a lethal process of organ procurement, with respect to the charge of wrongful exploitation it is difficult to see why it matters whether the donating individual is alive or dead, provided there is genuine consent.
The crux of the matter ethically centres on the possible legitimacy of lethal organ donation, in which vital organs are extracted from irreversibly comatose but still-living individuals before a planned withdrawal of life-sustaining treatment. Describing the transplant surgeon as an "executioner" does not serve moral clarity in approaching this issue. Jonas apparently saw a moral bright line between stopping lifesustaining treatment, thus (merely) allowing the patient to die and causing death by extracting vital organs. In this respect his position reflects prevailing medical ethics. Some ethicists, however, regard stopping life support for those who require it to continue living as patently a matter of causing death. ${ }^{18}$ According to this perspective, insisting that withdrawing lifesustaining treatment is a passive omission of treatment that merely allows the patient to die amounts to a "moral fiction"a morally motivated false belief-endorsed in order to preserve the absolute validity of the traditional norm that doctors must not kill patients. Given the ethical legitimacy of stopping lifesustaining treatment (despite causing death) on the grounds of self-determination and non-maleficence, it is far from obvious that any harm or wrong is done to patients diagnosed as having irreversible apnoeic coma (brain death) if their vital organs are donated, with proper consent, before stopping life-sustaining treatment. ${ }^{19}$ As the imminent and legitimate outcome from withdrawing life support is the patient's death, whether caused or allowed to occur, should we not be concerned about wasting the precious life-saving resource of vital organs? This concern about the consequences of failing to use an available resource might be considered the obverse of the charge of exploitation.

Is the life-saving medical progress represented by vital organ transplantation an optional goal? Jonas undoubtedly is right that progress is not morally imperative if it comes at the expense of violating human rights. Scientific and technological interventions aimed at promoting human well-being must be subject to deontological constraints. However, it is important not to beg the question concerning the wrongfulness of vital organ procurement from brain-dead but still-living patientswhether it is the sort of grave moral wrong that would make the "dazzling triumphs" of scientific progress "not worth having". In 1968 the progress from organ transplantation was anticipated but not achieved. However, if Jonas's position had prevailed, substantial medical progress in saving lives would have been deterred. This progress was ostensibly justified by means of invoking the moral fiction that brain death equals death of the human being - a fiction that Jonas presciently exposed. Whether we are prepared to persist in the practice of vital organ donation without the support of this fiction is the ethical situation that we now face.

\section{WHERE WE STAND TODAY}

Revisiting the still-provocative essays of Jonas on brain death and organ donation helps in mapping present and future ethical and policy options. Four options seem most salient. First, we can follow the lead of Jonas by adopting a stance of deontological rectitude that abandons vital organ procurement from brain-dead, but still-living patients. This position is logically tidy and unassailable if its major premise is endorsed: (1) doctors must not kill patients; (2) brain-dead patients are alive; (3) procuring vital organs from brain-dead patients would cause their death; therefore, (4) this practice is wrong and must cease. However, the validity of the first premise is debatable; and if applied consistently, it would have drastic consequences. For not only would it put a stop to the life-saving practice of vital organ transplantation using the organs of brain-dead 
individuals; it also arguably would rule out the routine practice of deliberately stopping life-sustaining treatment, assuming the reasonable, but unorthodox, view that this practice involves causing death. (A partial way out of this latter impasse might be afforded by putting timers on life-support technology, such as ventilators, as is practised in Israel, thus permitting a genuine omission of treatment that does not cause death by virtue of deciding not to restart life support.) ${ }^{20}$ In any case, the deleterious consequences of this position limited to vital organ donation from brain-dead patients are sufficient to give pause to anyone seriously considering its adoption. Beyond foregoing life-saving transplantations, these consequences include thwarting the preferences of people interested in organ donation in the event of catastrophic neurological injury such as brain death and of family members interested in making some good come out of an unexpected tragedy.

A second position attempts to justify vital organ donation while maintaining (at least nominally) the dead donor rule by appealing to a distinction between the death of the human being and the death of the biological organism. According to this position, Jonas is right that the brain-dead patient is biologically alive; however, what matters ethically with respect to vital organ procurement is whether the human being has ceased to exist. In this "higher brain" position, the permanent loss of consciousness is regarded as the death of the human being. ${ }^{21-23}$ Once human life has ceased, stopping life-sustaining treatment is appropriate (or imperative), and there can be no ethical objection to extracting vital organs beforehand.

Although attractive to some philosophers, this position is unlikely to garner a wide consensus. It was rejected by both the President's Commission in 1981 and the President's Council on Bioethics in 2008. Advocates of the mainstream whole brain standard of death have insisted that there is only one (essentially biological) concept of death, which encompasses both neurological and cardiopulmonary criteria. They have claimed, although unpersuasively, that the brain-dead body is really a breathing corpse or cadaver because it is truly a dead organism. The purpose of a standard for the determination of death has been to indicate decisively when a human body is a corpse, making it suitable for burial or cremation as well as a source of organs to benefit others. The higher brain position, by contrast, entirely severs the concept of death of the human being from the status of being a corpse, making it decidedly counterintuitive. Moreover, it faces diagnostic problems. When can we be certain that biologically alive human beings are dead because they have irreversibly lost the capacity for consciousness? Any move beyond the diagnostic criteria for brain death is fraught with peril, in view of emerging data on the neural functioning of patients in a persistent vegetative state. ${ }^{8}$ Nor is this position free of philosophical difficulties. It at least appears to conflate loss of personhood, or the loss of all value in existence, with death. Advocates of this position may respond that there is no conflation because death is not a univocal concept: the death of the human being does not equate to the death of the organism. ${ }^{23}$ However, apart from the strategic effort to uphold the dead donor rule while permitting vital organ donation from permanently unconscious patients, it is not clear why it is necessary or desirable to invoke two kinds of death on the human level, as distinct from the unitary concept of death that applies to the rest of the biological world. The concept of the death of the human being based on permanent loss of consciousness is not needed to justify stopping lifesustaining treatment, as this can be appropriate for mentally intact patients who view continued living in their condition as intolerable. $^{24} 25$

A third position justifies vital organ donation while retaining the traditional cardiopulmonary criteria for determining death by biting the bullet of abandoning the dead donor rule. ${ }^{19}$ As suggested above, this position sees vital organ procurement from "brain-dead" but still-living patients as exposing them neither to harm nor violating their rights as long as it is connected with a previous plan to stop life-sustaining treatment and proper consent, both for stopping treatment and organ donation. Stopping life-sustaining treatment when justified is a legitimate act of causing the patient's death; procuring vital organs before treatment withdrawal is justified on essentially the same ethical grounds of self-determination and nonmaleficence. ${ }^{19}$

Regardless of its theoretical and practical merits, this position will be staunchly resisted by all those who endorse the "sanctity" of human life and the related traditional norm of medical ethics that doctors must never kill (cause the death of) patients. Whether openly procuring vital organs from living patients would be accepted by the public is also in question. However, if press reports indicate how lay persons think about this issue, there is reason to think that many members of the public do not believe that brain death constitutes death, despite support for organ donation. For example, a recent news report of policemen killed in the line of duty, stated that "A police officer shot during a traffic stop was pronounced brain-dead but remained on life support. Oakland police spokesman Jeff Thomason... said that [officer] Hege was being kept alive while a final decision was made about donating his organs."26 The public by and large may consider brain-dead patients alive but "as good as dead", making it legitimate to procure their organs, with proper consent. ${ }^{27}$

It is important to acknowledge that informed consent for lethal organ donation under this third position differs from the current practice of informed consent for organ donation that is predicated on the assumption that the "brain-dead" patient is dead. Prospective consent of donors or contemporaneous consent of surrogates would need to be based on recognition that the donor diagnosed as "brain dead" remains alive and will die as the result of the process of organ procurement and/or stopping life-sustaining treatment. Would it be harder to obtain consent for vital organ donation from such patients who are recognised as still living? It is not clear that facing the truth about the status of "brain-dead" individuals would affect the willingness to provide consent, in view of the evidence suggesting that many people currently do not regard them as genuinely dead.

Finally, a fourth position upholds the status quo by insisting that brain death constitutes biological death of the human organism, despite powerful evidence to the contrary. No plausible and coherent account has been advanced to explain why brain-dead patients are dead, making this position the least intellectually satisfactory of the various options; however, it is likely to be the one that will prevail in the near future. This position can take the form of articulating some rationale that gives the appearance of making sense of dual neurological and cardiopulmonary criteria for death, as in the case of the novel account presented in the President's Council recent report, or simply insisting on the fact that brain death constitutes death has been established, as in the recent JAMA commentary on the 1968 report of the Harvard committee. ${ }^{8}$ The other positions, although superior in internal coherence, are apt to seem unpalatable. On the one hand, for most people it would be 
morally intolerable to put a stop to, or drastically curtail, vital organ donation. On the other hand, neither the higher brain standard nor openly abandoning the dead donor rule are likely to be acceptable to most ethicists and to professionals involved in critical care and transplantation.

Nevertheless, any semblance of a consensus over death and vital organ donation will be fragile and theoretically weak. Brain dead patients do not appear to be dead, and arguments that they really are dead do not inspire conviction. Hans Jonas got it right in 1968 regarding the living status of these patients; and he correctly discerned that efforts to explain their being dead on the grounds that the organism as a whole ceased to exist were dubious. Where do we go from here? We face an unsettled and unsettling situation characterised by the moral imperative to continue vital organ transplantation, the entrenched norm that doctors must not kill, and the increasingly transparent fiction that the brain dead are really dead. In at least the near future it is probable that we will continue to muddle through. In the longer run, the medical profession and society may, and should, be prepared to accept the reality and justifiability of lifeterminating acts in medicine in the context of stopping lifesustaining treatment and performing vital organ transplantation.

Funding: This research was supported by the Intramural Research Program of the Clinical Center, National Institutes of Health.

Competing interests: None.

The opinions expressed are the views of the author and do not necessarily reflect the policy of the National Institutes of Health, the Public Health Service, or the US Department of Health and Human Services.

Provenance and peer review: Not commissioned; externally peer reviewed.

\section{REFERENCES}

1. President's Council on Bioethics. 2008. Controversies in the determination of death. Washington, DC. www.bioethics.gov (accessed July 2009).

2. President's Commission for the Study of Ethical Problems in Medicine and Biomedical and Behavioral Research. Defining death: medical, legal and ethical issues in the determination of death. Washington, DC: Government Printing Office, 1981.

3. Veatch RM. The impending collapse of the whole-brain definition of death. Hastings Center Report 1993:23:18-24.
4. Truog RD. Is it time to abandon brain death? Hastings Center Report 1997;27:29-37.

5. Shewmon DA. Chronic 'brain death': meta-analysis and conceptual consequences. Neurology 1998;51:1538-45

6. Souza JP, Oliveria-Neto A, Surita FG, et al. The prolongation of somatic support in pregnant woman with brain-death: a case report. Reproductive Health 2006;3:3 doi:10.1186/1742-4755-3-3

7. Yeung P, McManus C, Tchabo J-G. Extended somatic support for a pregnant woman with brain death from metastatic malignant melanoma: a case report. J MaternalFetal Neonatal Med 2008;21:509-11.

8. Rosenberg RN. Consciousness, coma and brain death-2009. JAMA 2009:301:1172-4.

9. Youngner SJ. The definition of death. In: Steinbock B, ed. The Oxford handbook of bioethics. Oxford: Oxford University Press, 2007:285-303.

10. Ad Hoc Committee of the Harvard Medical School to Examine the Definition of Brain Death. A definition of irreversible coma. JAMA 1968;205:337-40.

11. Belkin GS. Brain death and the historical understanding of bioethics. J Hist Med Allied Sci 2003;58:325-61.

12. Stevens MLT. Bioethics in America. Baltimore: Johns Hopkins University Press, 2000:75-108.

13. President's Commission for the Study of Ethical Problems in Medicine and Biomedical and Behavioral Research. Deciding to forego life-sustaining treatment. Washington, DC: Government Printing Office, 1983.

14. Jonas H. Philosophical reflections on experimenting with human subjects. In: Freund PA, ed. Experimentation with human subjects. New York: George Braziller, 1970:1-31.

15. Jonas H. Against the stream: comments on the definition and redefinition of death In: Jonas H, ed. Philosophical essays. Chicago: University of Chicago Press, 1974:132-40.

16. Shewmon DA. Spinal shock and 'brain death': Somatic pathophysiological equivalence and implications for the integrative-unity rationale. Spinal Cord 1999;37:313-24.

17. Ramsey $\mathbf{P}$. On updating procedures for stating that a man has died. In: Ramsey $\mathrm{P}$ ed. The patient as person, 2nd edn. New Haven: Yale University Press, 2002:69

18. Miller FG, Truog RD, Brock DW. Moral fictions and medical ethics. Bioethics 2009; in press.

19. Miller FG, Truog RD. Rethinking the ethics of vital organ donation. Hastings Center Report 2008;38:38-46.

20. Ravitsky V. Timers on ventilators. BMJ 2005;330:415-17.

21. Green MB, Wikler D. Brain death and personal identity. Philos Public Affairs 1980;9:105-33.

22. Gervais KG. Redefining death. New Haven, CT: Yale University Press, 1986.

23. McMahan J. An alternative to brain death. J Law, Med Ethics 2006:34:44-8.

24. Powell T, Lowenstein B. Refusing life-sustaining treatment after catastrophic injury: ethical implications. J Law, Med Ethics 1996;24:54-61.

25. Miller FG. A planned death in the family. Hastings Center Report 2009;39:28-30.

26. Collins T, Leff L. Wounded Oakland officer brain-dead. The Washington Post, 23 March 2009, A4.

27. Siminoff LA, Burant C, Youngner SJ. Death and organ procurement: public beliefs and attitudes. Soc Sci Med 2004:59:2325-34. 